ScIDice

\section{Assessment Of Patients Undergoing Treatment For Single Tooth Crossbite - An Institutional Study}

Research Article

Sandhya. $\mathrm{A}^{1}$, Aravind Kumar Subramanian ${ }^{2 *}$, Senthil Murugan $\mathrm{P}^{3}$

${ }^{1}$ Saveetha Dental College and Hospitals, Saveetha Institute of Medical and Technical Sciences (SIMATS), Saveetha University, Chennai, India.

${ }^{2}$ Professor, Department of Orthodontics, Saveetha Dental College and Hospitals, Saveetha Institute of Medical and Technical Sciences (SIMATS), Saveetha University, Chennai, India.

${ }^{3}$ Associate Professor, Department of Orthodontics, Saveetha Dental college and Hospitals, Saveetha institute of medical and technical sciences (SIMATS), Saveetha University, Chennai, India.

\title{
Abstract
}

A Crossbite can involve a single tooth or a group of teeth. It is a discrepancy in the buccolingual relationship of the upper and lower teeth. Cross-bite can be seen commonly in orthodontic practice and most patients ignore the treatment for a single tooth crossbite. The aim of the present study was to determine the number of patients seeking orthodontic treatment for single tooth crossbite in a private dental college and hospitals. The study was conducted in a university set up sample consisting of all patients who underwent orthodontic treatment for single tooth crossbite from June 2019 - April 2020, were examined and included in our data collection. A total of 41190 patient records were screened, out of that 492 patients had crossbite. Among those 492 crossbite patients about 91 patients of single tooth crossbite were selected. About 12 patients have undergone orthodontic treatment for single tooth crossbite. The statistical analysis was done using SPSS software (SPSS version 21.0, SPSS, Chicago II, USA). The data was analysed using a chi- square test. The $\mathrm{p}$ value of less than 0.05 was considered to be statistically significant. In this study, we can contemplate that only $13.2 \%$ people have undergone orthodontic treatment for single tooth crossbite. In comparison, the female population $(22.2 \%)$ underwent more orthodontic treatment for single tooth crossbite than the male population despite the age group. There was a significant gender difference observed in the rising trend.( $\mathrm{p}$ value: 0.039 ( $>0.05$ statistically significant)

Keywords: Crossbite; Female Patients; Male Patients; Orthodontic Treatment; Single Tooth Crossbite.

\section{Introduction}

It is a discrepancy in the buccolingual relationship of the upper and lower teeth. Cross-bite can be seen commonly in orthodontic practice. It can be clinically identified, when the lower teeth are in a buccal or labial position regarding the upper teeth, in a unilateral, bilateral, anterior and/or posterior manner [1-3]. In the transverse dimension, normal occlusion is when the palatine cusps of the upper molars and premolars occlude in the fossa of lower molars and premolars. In the anteroposterior plane, the upper incisors occlude on the labial aspects of lower incisors. The term buccal crossbite refers to the buccal cusps of the lower teeth occlude buccal to the buccal cusps of the upper teeth. Scissor bite refers to the condition when the buccal cusps of the lower teeth occlude lingual to the lingual cusps of the upper teeth. Crossbite malocclusion can have a skeletal or dental component or combination of both.

A Crossbite can involve a single tooth or a group of teeth. Cross bite can be classified as anterior or posterior. Depending on the etiology and clinical presentation, anterior cross bite can be classified into three main types namely dento-alveolar, skeletal and functional $[4,5]$. Dento-alveolar anterior cross bite often involves a single tooth rather than multiple teeth. This simple anterior cross bite is mainly of dental origin and these patients have normal antero-posterior skeletal relationship. Skeletal anterior crossbite usually occurs as a result of a skeletal discrepancy in the maxilla (retrognathic) or the mandible (prognathic). Functional anterior crossbite is a type of pseudo class III malocclusion in which the mandible is postured forward from its true centric position. Sev-

\section{*Corresponding Author:}

Aravind Kumar Subramanian,

Professor, Department of Orthodontics, Saveetha Dental College and Hospitals, Saveetha Institute of Medical and Technical Sciences (SIMATS), Saveetha University, Chennai, India.

Tel : +919841299939

E-mail: aravindkumar@saveetha.com

Received: May 08, 2021

Accepted: June 16, 2021

Published: July 06, 2021

Citation: Sandhya.A, Aravind Kumar Subramanian, Senthil Murugan P.Assessment Of Patients Undergoing Treatment For Single Tooth Crossbite - An Institutional Study. Int J Dentistry Oral Sci. 2021;8(7):3069-3073. doi: http://dx.doi.org/10.19070/2377-8075-21000625

Copyright: Aravind Kumar Subramanian. ${ }^{\circ}$ 2021. This is an open-access article distributed under the terms of the Creative Commons Attribution License, which permits unrestricted use, distribution and reproduction in any medium, provided the original author and source are credited. 
eral factors are reported as causes of anterior cross bite, including a lingual eruption path of maxillary incisors, retained primary incisors, potential crowding, presence of supernumerary teeth, trauma and class III skeletal pattern.

Posterior cross bite is one of the most prevalent malocclusions in the primary and early mixed dentition and is reported to occur in $8 \%$ to $22 \%$ of the cases $[6,7]$. It is defined as any abnormal buccal- lingual relation between opposing molars, premolars, or both in centric occlusion. The most common form is a unilateral presentation with a functional shift of the mandible toward the crossbite side, which occurs in $80 \%$ to $97 \%$ of cases. The causes include any combination of dental, skeletal, and neuromuscular functional components, but the most frequent cause is reduction in width of the maxillary dental arch. Such reduction can be induced by finger sucking $[8,9]$ certain swallowing habits, or obstruction of the upper airways caused by adenoid tissues or nasal allergies $[10,11]$.

Single tooth crossbites can occur due to improper eruption of a primary tooth in a timely manner which causes permanent tooth to erupt in a different eruption pattern which is lingual to the primary tooth. Single tooth crossbites are often fixed by using finger-spring based appliances. Single tooth crossbites are not self-correcting and in some situations worsen during later stages of the dentition causing gingivitis, bone loss, periodontal problems. In severe cases, crossbites can affect jaw and face development, especially in young patients. In addition, a misaligned bite can leave a lasting mark escalating into a permanent deviation of the bones and skull on your face, speech impediments, and an unbalanced facial appearance. Many people are unaware of the need to correct single tooth crossbite. Previously our team has a rich experience in working on various research projects across multiple disciplines The [12-14, 15-26]. The main objective of this study is to evaluate the number of people and the negligence in undergoing single tooth crossbite correction. Hence this study was an attempt to find out the number of patients seeking orthodontic treatment for single tooth crossbite as there is no sufficient article regarding this issue.

\section{Materials And Method}

\section{Study setting and sampling}

This study is a single-center retrospective study, carried out in the Department of Orthodontics in a private dental college. The study was approved by the ethical board of Saveetha dental college - Institutional ethical committee [IEC] (SDC/SIHEC/2020/ DIASDATA/0619-0320) and was in accordance with the ethical standards that were stipulated. All available records of Orthodontic patients from June 2019 - April 2020, were examined and included in our data collection. A total of 41190 patient records were screened, out of that 492 patients had crossbite. Among those 492 crossbite patients about 91 patients of single tooth crossbite were selected. About 12 patients have undergone orthodontic treatment for single tooth crossbite. Cross verification of data for error was done by presence of additional reviewers and by photographs evaluation. Simple random sampling was done to minimise sampling bias. It was generalised to the south indian population. Two examiners were involved in the study.
Acquisition of data was done from the hospital digital database which records all patients details. The data were entered in the system in a methodical manner. For this study, Data on the number of single tooth crossbite orthodontic patients and clinical variables such as their gender, treatment prognosis were collected. The data was then entered in excel manually and imported to SPSS for analysis. Incomplete or censored data were excluded from the study.

\section{Statistical Analysis}

Descriptive statistics were used to summarise the demographic information of the patients included in this study. Descriptive statistics is used for the acquisition of frequency of distribution of the data. The statistical analysis was done using SPSS software (SPSS version 21.0, SPSS, Chicago II, USA). The data was analysed using a chi- square test. The $\mathrm{p}$ value of less than 0.05 was considered to be statistically significant.

\section{Results And Discussion}

It is observed that only $13.19 \%$ of the patients are willing and about $86.81 \%$ of the patients are not willing for the single tooth crossbite correction. (GRAPH 1) The highest frequency was observed in males $(60.44 \%)$ when compared to females $(39.56 \%)$. (GRAPH 2) It is observed that females have undergone more orthodontic treatment for single tooth crossbite. The $\mathrm{p}$ value was found to be 0.039 . There was a significant difference between the gender and treatment status of Single Tooth crossbite patients. (GRAPH 3) It is observed that people of age group 19-30 years have undergone more orthodontic treatment for single tooth crossbite. The $\mathrm{p}$ value was found to be 0.161 . There was a significant difference between the age and treatment status of Single Tooth crossbite patients.(GRAPH 4)

In the present study, it is observed that only few people seek orthodontic treatment for single tooth crossbite. There are studies that evaluate the prevalence of cross bite but not the treatment status of the subjects involved in the study.

In a study by Jalber Almeida dos Santos et al in Brazil it was observed that $28.1 \%$ of school children have crossbite. Highest frequency was seen among 13 year olds (39.3\%), followed by 14 year olds $(32.0 \%)$. Regarding the type of cross bite $45.9 \%$ had unilateral cross bite, while $34.4 \%$ had anterior cross-bite [27].

When analyzing the gender in this study there was a higher prevalence for the male gender (60\%). This finding distances itself from that found by Chowdhry et al(2019), which presented a tendency for females $(47 \%)$ [28].

In a study conducted to evaluate the effect of class III malocclusion and crossbite on Craniomandibular dysfunction based on a sample of 115 children and adolescent patients of both sexes it was found that of the total sample, the prevalence of crossbite was $30.4 \%$ [29].

Researchers during the occlusal development have reported that early decay and tooth loss, rotations, forward shift of the first molars, interferences, posterior crossbite, and mandibular shifts

\section{Data Collection/Tabulation}


predispose an individual to the development of the temporomandibular joint disorders and increase the sensitivity of the skeletal muscle. Williamson and Lundquist reported that interfering dental contacts have significant effects on volumetric muscle activity. A significant relationship was detected between the posterior crossbite and joint sounds, clicking, and muscle tenderness. Muscle tenderness is more common in children with crossbite than in children without crossbite [30]. Our institution is passionate about high quality evidence based research and has excelled in various fields [31-41].

Hence, there is a need for educating the people about the need for orthodontic correction for single tooth crossbite. The pros of the study includes flexibility, less time consumption and accessibility. The limitations of the study include varied population size and a distinct population group.

\section{Conclusion}

If left untreated, crossbites cause a series of health problems along with dental issues such as teeth grinding, irregular wear to the enamel, and loss of teeth and also crossbite patients report developing headaches and muscle tension from the abnormal stress placed on the jaw. In severe cases, crossbites can affect jaw and face development, especially in young patients. As we grow older, crossbite from childhood triggers severe pain in our jaw

Graph 1: The bar graph showing frequency of Treatment Status of Single Tooth crossbite patients. X Axis represents the Treatment Status and Y Axis represents the number of Single Tooth crossbite Patients. It is observed that most of the patients are not willing $(86.81 \%)$ for single tooth crossbite correction.

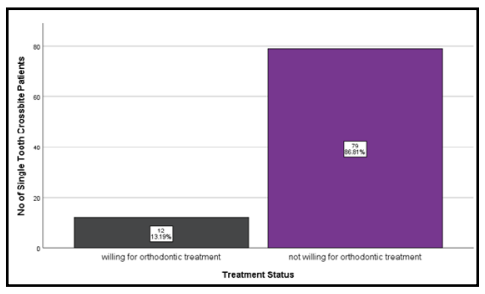

Graph 2: The bar graph showing frequency of gender wise distribution of Single Tooth cross bite patients. X Axis represents the gender and Y Axis represents the number of Single Tooth crossbite Patients. The highest frequency was observed in males $(60.44 \%)$ when compared to females $(39.56 \%)$.

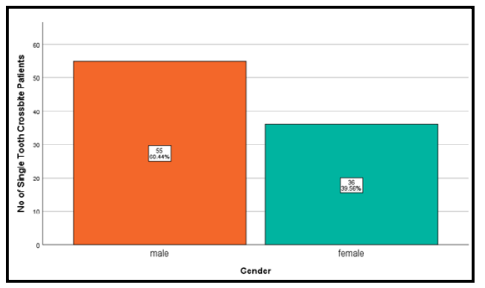

Graph 3: The bar graph represents the association of gender and Treatment Status of Single Tooth crossbite patients. The highest frequency was noted among females when compared to males. It is observed that only a considerable amount of patients were willing for single tooth crossbite correction. There was a significant difference between the gender and treatment status of Single Tooth crossbite patients.(Chi - Square, $p$ value: 0.039 ( $p<0.05$ statistically significant)).

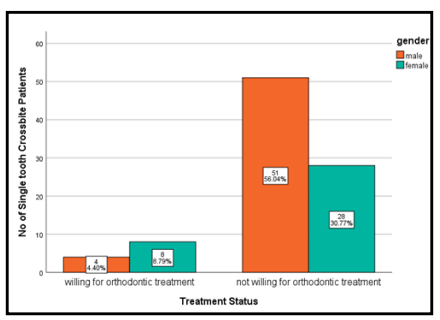

Graph 4: The bar graph represents the association of age and Treatment Status of Single Tooth crossbite patients. It is observed that people of age group 19 to 30 years and 7 to 18 years have undergone single tooth crossbite correction. Among those majority of the people willing for the treatment belong to the age group 19-30 years. There was a significant difference between the age and treatment status of Single Tooth crossbite patients. (Chi - Square, $p$ value: 0.161 ( $p<0.05$ statistically significant)).

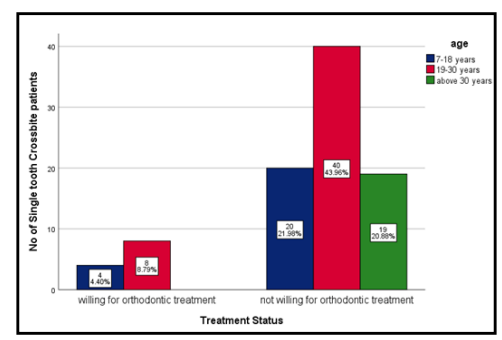


joint and supporting muscles hence it is advised to correct crossbite at an early stage to enhance their chances of full correction and avoid any further shifts or deviations in their bite. Within the limits of the study, it was observed Only a considerable amount of people are willing to undergo single tooth crossbite correction hence there is a need for educating the people and the dentist about the need and importance of orthodontic correction for single tooth crossbite.

\section{Authors Contribution}

First author, Sandhya performed the data collection by reviewing patient details, filtering required data, analysing and interpreting statistics and contributed to manuscript writing.

Second author, Dr. Aravind Kumar Subramanian contributed to conception of study title, study design, analysed the collected data, statistics and interpretation and also critically revised the manuscript.

Third author, Dr. Senthil Murugan P participated in the study and revised the manuscript. All the three authors have discussed the results and contributed to the final manuscript.

\section{Acknowledgement}

This research was supported by saveetha dental college and hospital. We thank the department of Orthodontics, Saveetha Dental College for providing insight and expertise that greatly assisted this research.

\section{References}

[1]. Sollenius O, Petrén S, Bondemark L. An RCT on clinical effectiveness and cost analysis of correction of unilateral posterior crossbite with functional shift in specialist and general dentistry. Eur J Orthod. 2019. Available from:

[2]. Asiry MA, AlShahrani I. Prevalence of malocclusion among school children of Southern Saudi Arabia. J. Orthod. Sci. 2019;8:2.

[3]. Yu X, Zhang H, Sun L, Pan J, Liu Y, Chen L. Prevalence of malocclusion and occlusal traits in the early mixed dentition in Shanghai, China. PeerJ. 2019 Apr 2;7:e6630.Pubmed PMID: 30972246.

[4]. Bs P, Phulari BS, Rashanal A. Interceptive Orthodontics. Orthodontics: Principles and Practice. 2017.195. Available from:

[5]. Millett D, Day P. Clinical Problem Solving in Orthodontics and Paediatric Dentistry E-Book. Elsevier Health Sciences; 2010 Oct 18:224.

[6]. Kutin G, Hawes RR. Posterior cross-bites in the deciduous and mixed dentitions. Am. J. Orthod. 1969 Nov 1;56(5):491-504.

[7]. Egermark-Eriksson I, Carlsson GE, Magnusson T, Thilander B. A longitudinal study on malocclusion in relation to signs and symptoms of craniomandibular disorders in children and adolescents. Eur J Orthod. 1990 Nov;12(4):399-407.Pubmed PMID: 2086260.

[8]. Andrade AS, Gameiro GH, DeRossi M, Gaviāo MB. Posterior crossbite and functional changes: a systematic review. Angle Orthod. 2009 Mar;79(2):3806.

[9]. Thilander B, Wahlund S, Lennartsson B. The effect of early interceptive treatment in children with posterior cross-bite. Eur J Orthod. 1984 Jan $1 ; 6(1): 25-34$.

[10]. Linder-Aronson S. Effects of adenoidectomy on mode of breathing, size of adenoids and nasal airflow. ORL J Otorhinolaryngol Relat Spec. 1973;35(5):283-302.Pubmed PMID: 4795962.

[11]. Hannuksela A, Väänänen A. Predisposing factors for malocclusion in 7-yearold children with special reference to atopic diseases. Am J Orthod Dentofacial Orthop. 1987 Oct;92(4):299-303.Pubmed PMID: 3477948.

[12]. Hafeez N. Accessory foramen in the middle cranial fossa. Res J Pharm Technol. 2016;9(11):1880-2.

[13]. Krishnan RP, Ramani P, Sherlin HJ, Sukumaran G, Ramasubramanian A, Jayaraj G, et al. Surgical Specimen Handover from Operation Theater to Laboratory: A Survey. Ann Maxillofac Surg. 2018 Jul-Dec;8(2):234-238.
Pubmed PMID: 30693238.

[14]. Somasundaram S, Ravi K, Rajapandian K, Gurunathan D. Fluoride Content of Bottled Drinking Water in Chennai, Tamilnadu. J Clin Diagn Res. 2015 Oct;9(10):ZC32-4.Pubmed PMID: 26557612.

[15]. Felicita AS. Orthodontic extrusion of Ellis Class VIII fracture of maxillary lateral incisor - The sling shot method. Saudi Dent J. 2018 Jul;30(3):265269.Pubmed PMID: 29942113.

[16]. Kumar S, Rahman R. Knowledge, awareness, and practices regarding biomedical waste management among undergraduate dental students. Asian J Pharm Clin Res. 2017;10(8):341.

[17]. Gurunathan D, Shanmugaavel AK. Dental neglect among children in Chennai. J Indian Soc Pedod Prev Dent. 2016 Oct 1;34(4):364.

[18]. Sneha $S$. Knowledge and awareness regarding antibiotic prophylaxis for infective endocarditis among undergraduate dental students. Asian J Pharm Clin Res. 2016 Oct 1:154-9.

[19]. Dhinesh B, Lalvani JI, Parthasarathy M, Annamalai K. An assessment on performance, emission and combustion characteristics of single cylinder diesel engine powered by Cymbopogon flexuosus biofuel. Energy Convers. Manag. 2016 Jun 1;117:466-74.

[20]. Choudhari S, Thenmozhi MS. Occurrence and Importance of Posterior Condylar Foramen. Res J Pharm Technol. 2016;9(8):11-43.

[21]. Paramasivam A, Vijayashree Priyadharsini J, Raghunandhakumar S. N6adenosine methylation $(\mathrm{m} 6 \mathrm{~A})$ : a promising new molecular target in hypertension and cardiovascular diseases. Hypertens Res. 2020 Feb;43(2):153154.Pubmed PMID: 31578458.

[22]. Wu F, Zhu J, Li G, Wang J, Veeraraghavan VP, Krishna Mohan S, et al. Biologically synthesized green gold nanoparticles from Siberian ginseng induce growth-inhibitory effect on melanoma cells (B16). Artif Cells Nanomed Biotechnol. 2019 Dec;47(1):3297-3305.Pubmed PMID: 31379212.

[23]. Palati S, Ramani P, Shrelin HJ, Sukumaran G, Ramasubramanian A, Don $\mathrm{KR}$, et al. Knowledge, Attitude and practice survey on the perspective of oral lesions and dental health in geriatric patients residing in old age homes. Indian J Dent Res. 2020 Jan-Feb;31(1):22-25.Pubmed PMID: 32246676.

[24]. Saravanan M, Arokiyaraj S, Lakshmi T, Pugazhendhi A. Synthesis of silver nanoparticles from Phenerochaete chrysosporium (MTCC-787) and their antibacterial activity against human pathogenic bacteria. Microb Pathog. 2018 Apr;117:68-72.Pubmed PMID: 29427709.

[25]. Govindaraju L, Gurunathan D. Effectiveness of Chewable Tooth Brush in Children-A Prospective Clinical Study. J Clin Diagn Res. 2017 Mar;11(3):ZC31-ZC34.Pubmed PMID: 28511505.

[26]. Vijayakumar Jain S, Muthusekhar MR, Baig MF, Senthilnathan P, Loganathan S, Abdul Wahab PU, et al. Evaluation of Three-Dimensional Changes in Pharyngeal Airway Following Isolated Lefort One Osteotomy for the Correction of Vertical Maxillary Excess: A Prospective Study. J Maxillofac Oral Surg. 2019 Mar;18(1):139-146.Pubmed PMID: 30728705.

[27]. Almeida AB, Leite IC. Orthodontic treatment need for Brazilian schoolchildren: a study using the Dental Aesthetic Index. Dental Press J Orthod. 2013;18:103-9.

[28]. Chowdhury MS, Sultana N, Naim MA, Nashrin T, Nahar L. Prevalence of Cross Bite among the Orthodontic Patients at a Dental Unit of Bangladesh. J Natl Inst Neurosci Bangladesh. 2019 Sep 7;5(2):167-71.

[29]. Popovic N, Drinkuth N, Toll DE. Prevalence of class III malocclusion and crossbite among children and adolescents with craniomandibular dysfunction. J. orofac. Orthop./Fortschr. Kieferorthop. 2014 Jan 1;75(1):36-41

[30]. Bilgiç F, Gelgör İE. Prevalence of temporomandibular dysfunction and its association with malocclusion in children: an epidemiologic study. J. Clin. Pediatr. Dent. 2017;41(2):161-5.

[31]. Vijayashree Priyadharsini J. In silico validation of the non-antibiotic drugs acetaminophen and ibuprofen as antibacterial agents against red complex pathogens. J Periodontol. 2019 Dec;90(12):1441-1448.Pubmed PMID: 31257588.

[32]. Pc J, Marimuthu T, Devadoss P, Kumar SM. Prevalence and measurement of anterior loop of the mandibular canal using CBCT: A cross sectional study. Clin Implant Dent Relat Res. 2018 Apr 6;20(4):531-4.

[33]. Ramesh A, Varghese S, Jayakumar ND, Malaiappan S. Comparative estimation of sulfiredoxin levels between chronic periodontitis and healthy patients - A case-control study. J Periodontol. 2018 Oct;89(10):1241-1248.Pubmed PMID: 30044495.

[34]. Ramadurai N, Gurunathan D, Samuel AV, Subramanian E, Rodrigues SJ. Effectiveness of 2\% Articaine as an anesthetic agent in children: randomized controlled trial. Clin Oral Investig. 2019 Sep;23(9):3543-50.

[35]. Sridharan G, Ramani P, Patankar S, Vijayaraghavan R. Evaluation of salivary metabolomics in oral leukoplakia and oral squamous cell carcinoma. J Oral Pathol Med. 2019 Apr;48(4):299-306.

[36]. Ezhilarasan D, Apoorva VS, Ashok Vardhan N. Syzygium cumini extract induced reactive oxygen species-mediated apoptosis in human oral squamous carcinoma cells. J Oral Pathol Med. 2019 Feb;48(2):115-121.Pubmed 
PMID: 30451321.

[37]. Mathew MG, Samuel SR, Soni AJ, Roopa KB. Evaluation of adhesion of Streptococcus mutans, plaque accumulation on zirconia and stainless steel crowns, and surrounding gingival inflammation in primary molars: randomized controlled trial. Clin Oral Investig. 2020 Sep;24(9):1-6.Pubmed PMID: 31955271.

[38]. Samuel SR. Can 5-year-olds sensibly self-report the impact of developmental enamel defects on their quality of life? Int J Paediatr Dent. 2021 Mar;31(2):285-286.Pubmed PMID: 32416620.

[39]. R H, Ramani P, Ramanathan A, R JM, S G, Ramasubramanian A, et al. CYP2 C9 polymorphism among patients with oral squamous cell carcinoma and its role in altering the metabolism of benzo[a]pyrene. Oral Surg Oral
Med Oral Pathol Oral Radiol. 2020 Sep;130(3):306-312.Pubmed PMID: 32773350.

[40]. Chandrasekar R, Chandrasekhar S, Sundari KKS, Ravi P. Development and validation of a formula for objective assessment of cervical vertebral bone age. Prog Orthod. 2020 Oct 12;21(1):38.Pubmed PMID: 33043408.

[41]. Vijayashree Priyadharsini J, Smiline Girija AS, Paramasivam A. In silico analysis of virulence genes in an emerging dental pathogen A. baumannii and related species. Arch Oral Biol. 2018 Oct;94:93-98.Pubmed PMID: 30015217 . 